\title{
SIZE AND TEMPERATURE DEPENDENCE OF THE SURFACE PLASMON RESONANCE IN SILVER NANOPARTICLES
}

\author{
O.A. YESHCHENKO,${ }^{1}$ I.M. DMITRUK, ${ }^{1}$ A.A. ALEXEENKO,${ }^{2}$ A.V. KOTKO,${ }^{3}$ \\ J. VERDAL, ${ }^{4}$ A.O. PINCHUK ${ }^{4}$ \\ ${ }^{1}$ Physics Department, Taras Shevchenko National University of Kyiv \\ (4, Prosp. Academician Glushkov, Kyiv 03127, Ukraine; e-mail: yes@univ. kiev. ua)
}

${ }^{2}$ Laboratory of Technical Ceramics and Silicates, Gomel State Technical University (48, October Prosp., Gomel 246746, Belarus)

${ }^{3}$ I.M. Frantsevich Institute for Problems of Materials Science (3, Krzhizhanovsky Str., Kyiv 03680, Ukraine)

PACS 73.20.Mf, 78.67.Bf, 65.80.-g (C) 2012

${ }^{4}$ Department of Physics and Energy Sciences, University of Colorado at Colorado Springs (1420 Austin Bluffs Pkwy, Colorado Springs, Colorado 80933, USA)

\begin{abstract}
The size and temperature dependences of the surface plasmon energy are studied for silver nanoparticles embedded in a silica host matrix in the size range $11-30 \mathrm{~nm}$ and in the temperature interval 293-650 K. It is revealed that the surface plasmon energy in studied silver nanoparticles depends on the size and the temperature of nanoparticles. As the size of nanoparticles decreases or the temperature increases, the surface plasmon resonance shifts to the red side. When the size of nanoparticles decreases, the rate of scattering of the conduction electrons on the nanoparticle surface increases, which results in a nonlinear red shift of the surface plasmon resonance. The temperature dependence of the red shift is linear for larger nanoparticles and becomes nonlinear for smaller ones. It is shown that the volume thermal expansion of nanoparticles leads to a red shift of the surface plasmon resonance, as the temperature increases. It is revealed that the thermal volume expansion coefficient depends on the size and the temperature. It increases with decrease of the nanoparticle size and with increase of the temperature.
\end{abstract}

\section{Introduction}

Noble metal nanoparticles have attracted a lot of attention recently due to a wide range of potential applications in Surface Enhanced Raman Scattering (SERS) [1-3], surface enhanced fluorescence [4-6], biochemical imaging [7-9], cancer treatment [7,10-12], and subwavelength optical waveguides [13-17], to name just a few. The size confinement of conduction electrons is the factor that influences considerably the optical and electronic properties of metal nanoparticles [18-21]. Size effects influence both the position and the width of the collective coherent excitation of free electrons, known as the Surface Plasmon Resonance (SPR) band [18, 19, 22]. There are two different effects in metal nanoparticles: external and internal size effects. The external, or electrodynamics size effect, is caused by the retardation of electromagnetic waves and can be rationalized by the Mie theory [23]. The confinement of conduction electrons inside the nanoparticles leads to the scattering of electrons on the surface of a particle and results in the internal size effect $[19,24]$.

The size effect on the width of SPR excitation in metal nanoparticles is well understood and results in the broadening of the SPR band for very small and for large nanoparticles [19]. The size confinement of the conduction electrons in metal nanoparticles broadens the SPR band $[18,19,23]$. The increase of the bandwidth with decrease of the nanoparticle size is caused by the scattering of te conduction electrons on the surface of a nanoparticle. When the nanoparticle size increases, the SPR band broadens again due to the radiation damping [6, 25-27]. The width of the SPR is a very important factor determining, for example, the local field enhancement due to the SPR excitation, which is used in surface enhanced spectroscopy. Meanwhile, the size dependence of the SPR energy is somewhat ambiguous [18]. Though the classical electrodynamics theory, such as the Mie theory, predicts a blue shift for the SPR, when the nanoparticle size decreases, some experiments revealed different shifts of the SPR frequency. There are reports on both blue shift and red shift of the SPR frequency, as the size of nanoparticles decreases [18, 28, 29].

In addition to the size effect, the increase of the temperature of nanoparticles leads to an additional shift of the SPR band and its broadening [18]. The temperature and size dependence of the SPR band is crucial for 
pure and applied science of nanoparticles [18,30]. The temperature dependence of the SP resonance is important because of the recent applications of noble metal nanoparticles in the thermally assisted magnetic recording [31], thermal cancer treatment [12,32-34], catalysis, nanostructure growth [35], and computer chips [36]. The underlying physics of the size dependence of nanoparticle parameters such as the coefficient of thermal expansion is a precondition for the development of successful and reliable applications and devices. The temperature effects were addressed by many authors [18, 37]. The size effects in the temperature dependence of the SPR absorption band was studied, e.g., by Kreibig [18] and Doremus [38]. Most of the effects related to the temperature dependence of the SPR was observed at low temperatures [18]. Link and El-Sayed studied the size and temperature dependence of the SPR wavelength and the bandwidth for gold colloidal nanoparticles [39]. Gold colloidal nanoparticles within the size range of $9 \mathrm{~nm}$ up to $99 \mathrm{~nm}$ were studied at elevated temperatures up to $72{ }^{\circ} \mathrm{C}$. No significant influence of the temperature on the SPR wavelength and bandwidth was found.

In this paper, we present experimental results on the size and temperature dependence of the SPR energy in silver nanoparticles embedded in silica. As the size of nanoparticles decreases, the SPR shifts to the red side. We show that this shift is caused by the size dependence of the scattering rate of free electrons in silver nanoparticles. An increase of the temperature of the sample leads to the red shift of the SPR. We show that it is caused by the thermal volume expansion of the nanoparticles with increasing temperature.

The paper is organized as following. After Introduction, we give a description of the procedure of synthesis of nanoparticles, as well as the structural and optical characterizations of silver nanoparticles. Section 3 describes the experimental observations of the red shift of the SPR at a decrease of the nanoparticle size and an increase of the temperature. Section 4 outlines a simple theory of the size and temperature dependences of the SPR energy. Section 5 discusses the significance of different mechanisms leading to the shift of the SPR followed by Conclusions.

\section{Synthesis of Silver Nanoparticles and Their Optical and Structural Characterizations}

\subsection{Synthesis}

We used the published experimental procedure [40-42] to synthesize silver nanoparticles of various sizes embed- ded in a silica host matrix. Composite $\mathrm{Ag} / \mathrm{SiO}_{2}$ samples containing the silver nanoparticles were produced using a modified conventional sol-gel technique based on the hydrolysis of tetraethoxysilane (TEOS) with doping followed by a chemical transformation of the dopants in air or a controlled gaseous medium. A precursor sol was prepared by the mixing of TEOS, water, and alcohol with the acid catalysts $\mathrm{HNO}_{3}$ or $\mathrm{HCl}$. Silica powder with particle size about $5-15 \mathrm{~nm}$ was added to the sol followed by the ultrasonication in order to prevent a large volume contraction during drying. The next gelation step resulted in the formation of gels. Porous materials (xerogels) were obtained after the gels were dried at room temperature. The porosity of $\mathrm{SiO}_{2}$ matrices was controlled by annealing the samples in air at a temperature of $600{ }^{\circ} \mathrm{C}$ during $1 \mathrm{~h}$. The silver doping was performed by the immersion of xerogels into an $\mathrm{AgNO}_{3}$ alcohol solution during $24 \mathrm{~h}$. We used the $\mathrm{AgNO}_{3}$ alcohol solutions with three concentrations: $0.15 \mathrm{mmol}\left(\mathrm{AgNO}_{3}\right) / 50 \mathrm{ml}$ (alcohol), $0.30 \mathrm{mmol} / 50 \mathrm{ml}$, and $0.45 \mathrm{mmol} / 50 \mathrm{ml}$. Then, the silver-doped samples were dried in air at $40{ }^{\circ} \mathrm{C}$ during $24 \mathrm{~h}$. The further processing of the Ag-doped xerogels was done in two different ways: (1) annealing in air with a gradual increase of the temperature from $20^{\circ} \mathrm{C}$ to $1200{ }^{\circ} \mathrm{C}$; (2) the same procedure but performed in the hydrogen atmosphere. The annealing resulted in the reduction of $\operatorname{Ag}(\mathrm{I})$ to $\mathrm{Ag}(0)$ and then in the aggregation of $\mathrm{Ag}$ atoms in the form of $\mathrm{Ag}$ nanoparticles. The samples obtained by the annealing in air had a low optical density and were non-colored (labeled hereafter as samples A), and the samples obtained using the annealing in the hydrogen atmosphere had a higher optical density and had yellow color (labeled as samples $\mathrm{H}$ ). We fabricated five samples: A0.30, A0.45 and H0.15, H0.30, H0.45 corresponding to different concentrations of $\mathrm{AgNO}_{3}$ in the alcohol solution mentioned above.

\subsection{Structural characterization}

The transmission electron microscopy (TEM) of fabricated $\mathrm{Ag} / \mathrm{SiO}_{2}$ glass samples was done to determine the size and shape distributions of nanoparticles. The TEM characterization was performed using a JEOL 100CX electron microscope operating at $100 \mathrm{kV}$. Figure 1 shows some examples of the TEM images of silver nanoparticles. The TEM measurements were performed for the powdered pieces of $\mathrm{Ag} / \mathrm{SiO}_{2}$ glass samples. The TEM images were taken from the edges of fragments of the powder, since only the edge can be probed (transmitted) by the TEM electron beam. Therefore, different areas of TEM images have different thicknesses and con- 

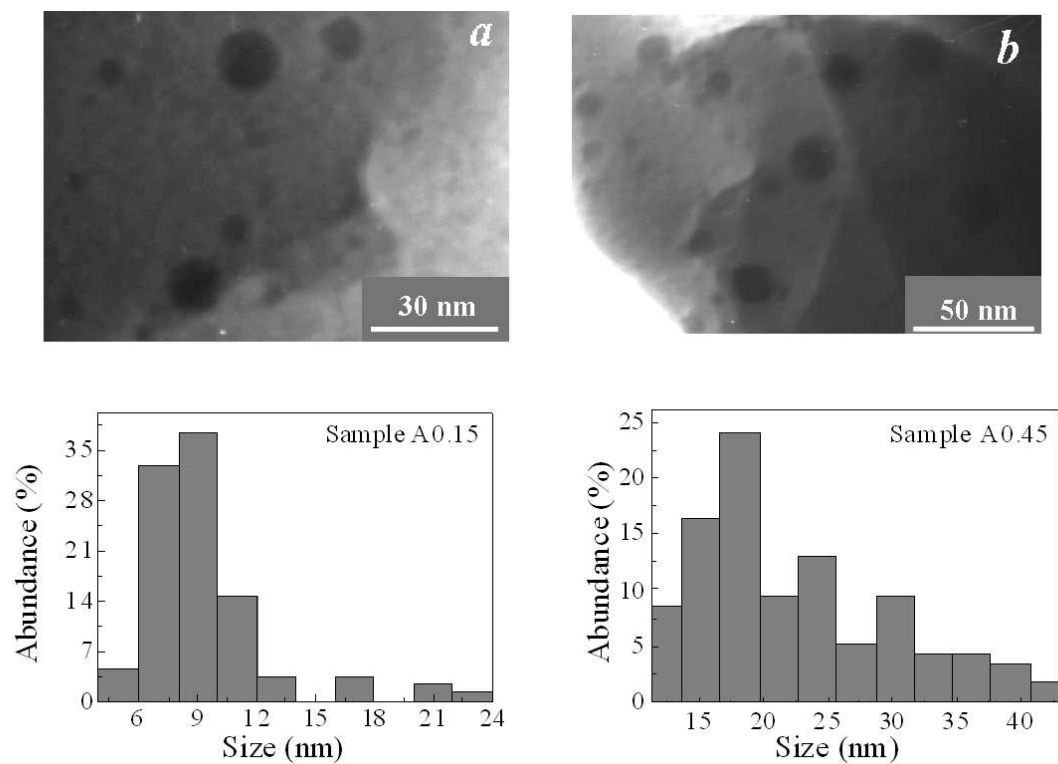
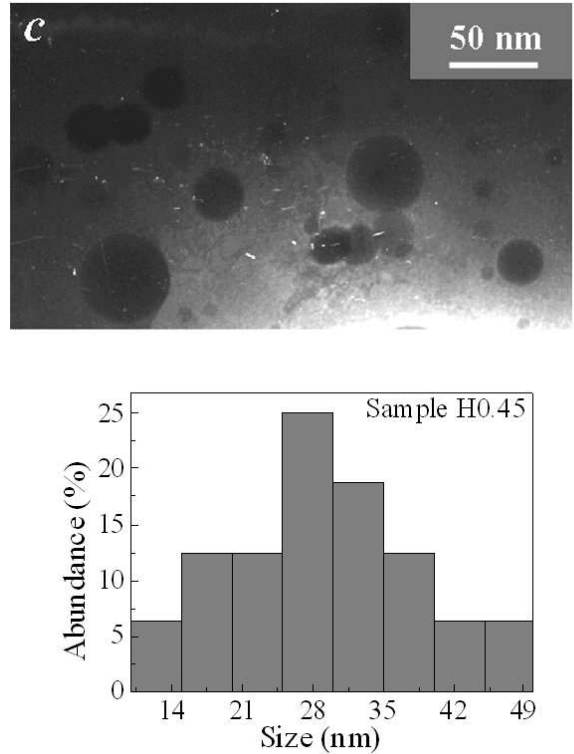

Fig. 1. TEM images with corresponding size distribution histograms of silver nanoparticles in silica glass for samples A0.15 (a) and A0.45 (b) annealed in air, and H0.45 (c) annealed in hydrogen

trasts. The size distributions of silver nanoparticles in different samples were obtained by analyzing 40-140 nanoparticles, depending on the sample. The nanoparticles are isolated and have spherical shape, and the diameter of particles was estimated for different samples as: sample A0.30 $(\langle d\rangle=11 \mathrm{~nm}$ with standard deviation $\left.\sigma_{d}=4 \mathrm{~nm}\right)$, A0.45 ( $\langle d\rangle=17 \mathrm{~nm}$ with $\left.\sigma_{d}=6 \mathrm{~nm}\right), \mathrm{H} 0.15$ $\left(\langle d\rangle=22 \mathrm{~nm}\right.$ with $\left.\sigma_{d}=9 \mathrm{~nm}\right), \mathrm{H} 0.30(\langle d\rangle=26 \mathrm{~nm}$ with $\left.\sigma_{d}=10 \mathrm{~nm}\right)$ and H0.45 $\left(\langle d\rangle=30 \mathrm{~nm}\right.$ with $\left.\sigma_{d}=13 \mathrm{~nm}\right)$. The TEM results indicate a large separation between nanoparticles exceeding the particle size from several times to several tens times. Thus, the electrodynamical coupling does not affect their optical spectra. One can see that the increase of the concentration of salt $\mathrm{AgNO}_{3}$ in initial xerogel and the annealing in hydrogen lead to the formation of larger silver nanoparticles.

\subsection{Optical Characterization}

A tungsten-halogen incandescent lamp was used as a light source for the absorption and diffuse reflectance (DR) measurements. A single grating spectrometer MDR-3 was used for the registration of the spectra. Since the measurements of the absorption spectra of silver nanoparticles were hindered by the scattering of light by the host medium, we studied the experimental DR spectra of the composites, which give the spectral dependence of the light scattering efficiency by the samples. We used diffuse reflectance spectra because, in the common (mirror) reflection spectra, the low intensity of the SPR band is mixed with the high intensity of the reflected lamp beam. Therefore, it is difficult to extract the low-intensity SPR band in the mirror reflection spectrum. In the diffuse reflectance spectrum, the intense background (lamp beam) is absent, and the SPR band can be easily measured. During the DR spectra measurements, the mirror-reflected light beam did not pass into the lens collecting the scattered light, which allowed us to exclude the intense background of reflected light. The angular dependence of the intensity of scattered light has maxima at $\theta=0$ and $180^{\circ}$. Therefore, we used the near-backscattering geometry of scattering spectra. DR spectra were recorded in the near-backscattering geometry, where the angle between the incident and reflected beams was about $15^{\circ}$.

The scattering of light by the matrix is due to the presence of nano-sized bubbles of gases in the matrix as a result of the annealing of the samples. The scattering indicatrix of our samples proves this assumption, as the experimental indicatrix is well fitted by the calculated one obtained for a model which includes three components in the system: silica matrix, silver nanoparticles, and nano-sized gas bubbles.

\section{Experimentally Observed Size and Temperature Changes in the SPR's Spectral Characteristics}

The DR spectra for various sizes of nanoparticles and temperatures are shown in Fig. 2. The SPR band can 

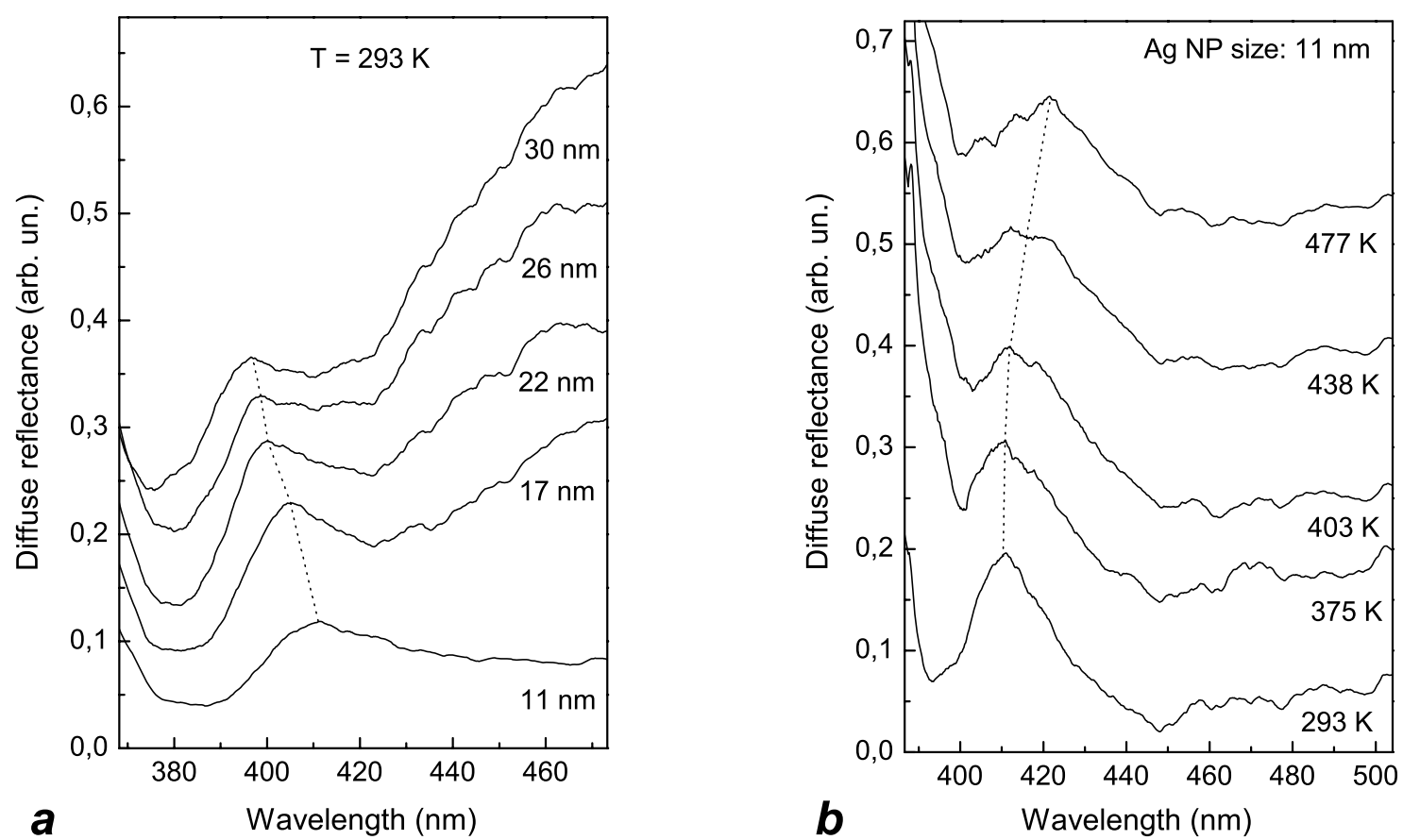

Fig. 2. Diffuse reflectance spectra in near-backscattering geometry of $\mathrm{Ag} / \mathrm{SiO}_{2}$ nanocomposite glasses containing silver nanoparticles of various sizes measured at a temperature of $293 \mathrm{~K}(a)$ and diffuse reflectance spectra of the $\mathrm{Ag} / \mathrm{SiO} 2$ sample containing the silver nanoparticles of 11-nm size measured at various temperatures $(b)$. The dotted line shows the shift of the SPR with changing size ( $a$ ) and temperature $(b)$

be identified as peaks at $395-410 \mathrm{~nm}$ depending on the sample, which is typical of silver nanoparticles embedded in silica $[18,43]$. Since the experimental spectral positions of the SP band in our samples coincide with the common values of the SPR spectral position for Ag nanoparticles in monolithic silica, we can conclude that the Ag nanoparticles in the studied samples are entirely surrounded by silica, and the gas bubbles are located between nanoparticles. In addition, as we have shown in our previous study [44] of the low-temperature melting of $\mathrm{Ag}$ nanoparticles in the same samples as studied in present work, the full reversibility of the spectra is observed at several cycles of heating and cooling up to temperatures exceeding ones reached in the present experiments. So, we conclude that no diffusion of melted $\mathrm{Ag}$ nanoparticles has occurred in our melting experiments. It is the additional evidence that $\mathrm{Ag}$ nanoparticles are entirely surrounded by solid silica in the studied samples. Thus, we can finally conclude that the observed band in DR spectra located at 395-410 nm, depending on the sample, corresponds to the $\mathrm{SR}$ resonance in $\mathrm{Ag}$ nanoparticles in silica.

Below, we analyze the size and temperature dependences of the SPR peak that is identified from the total DR spectrum. We determined the SPR energy and the bandwidth based on the decomposition of the DR spectra by using Lorentzian spectral contours. The errors in the decomposition of the SPR spectral band were small, specifically the error in the determination of the SPR energy was within $1 \%$. In the determination of the SPR bandwidth, the error was within 5\%. Therefore, the SPR peak was isolated from other bands quite accurately. This allows us to obtain the reliable size and temperature dependences of the SPR energy and bandwidth despite the broad size distribution of $\mathrm{Ag}$ nanoparticles.

As the size of the nanoparticles decreases, the SPR shifts from $395 \mathrm{~nm}$ for $30-\mathrm{nm}$ nanoparticles to $410 \mathrm{~nm}$ for 11-nm ones, see Fig. 2, $a$. Figure 3, $a$ depicts the size dependences of the SPR energy for silver nanoparticles at several temperatures: $293 \mathrm{~K}, 375 \mathrm{~K}$, and $477 \mathrm{~K}$. The red shift of the SPR contradicts the electrodynamics calculations according to the Mie theory, which usually give a blue shift of the SPR as the size of particles decreases $[18,45]$. We discuss the unusual shift of the SPR in details in the next sections. Figure $2, b$ shows the temperature dependence of the DR spectra of the $\mathrm{Ag} / \mathrm{SiO}_{2}$ sample containing silver nanoparticles of $11-\mathrm{nm}$ size. The increase of the temperature of the sample from $273 \mathrm{~K}$ up to $477 \mathrm{~K}$ leads to a red shift of the SPR. Figure $3, b)$ shows the nonlinear dependence of the SPR energy 


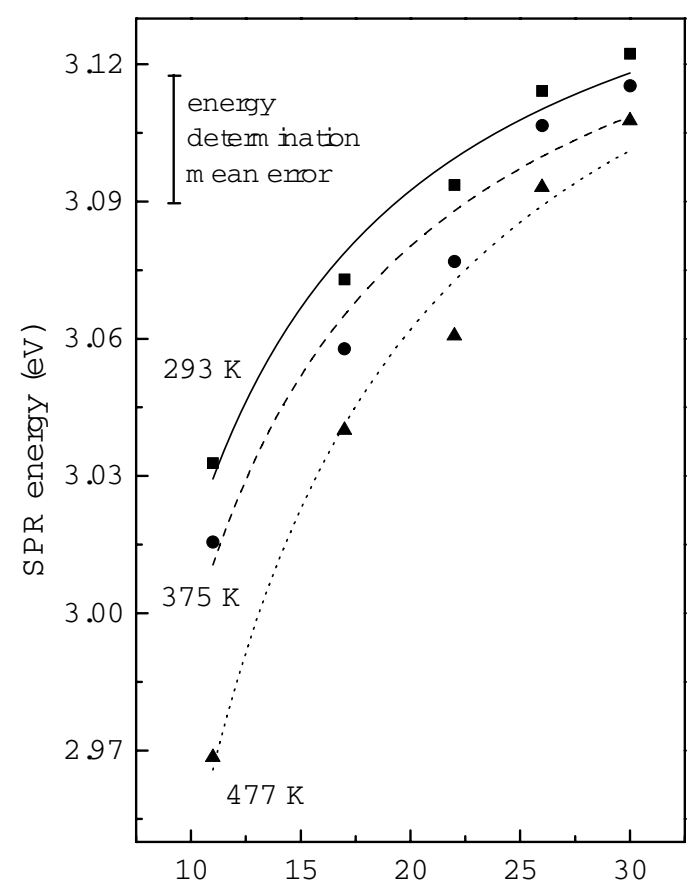

a

Size (nm)

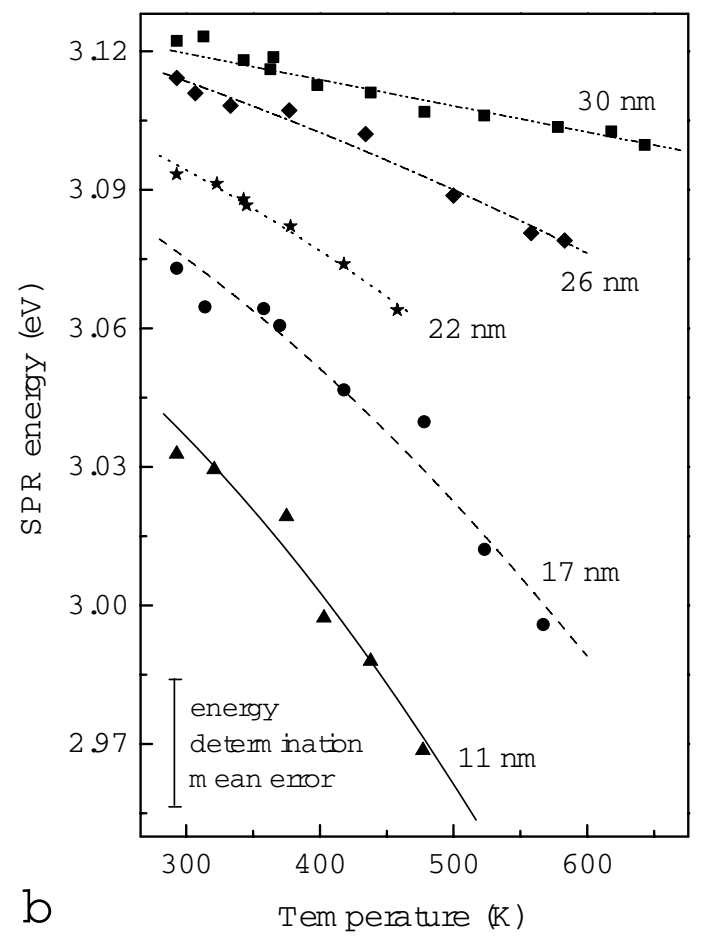

Fig. 3. (a) Size dependences of the SPR energy in silver nanoparticles in silica measured at various temperatures. The experimental points are fitted by expression (17). (b) Temperature dependences of the SPR energy for silver nanoparticles of various sizes. The experimental points are fitted by expression $(20)$

on the temperature for different sizes of nanoparticles: $11 \mathrm{~nm}, 17 \mathrm{~nm}, 22 \mathrm{~nm}, 26 \mathrm{~nm}$, and $30 \mathrm{~nm}$.

Figure 4 shows the size and temperature dependences of the SPR bandwidth. It is seen from Fig. 4, $a$ that a decrease of the nanoparticle size leads to the broadening of the SPR band. Such a dependence is described by the well-known $1 / R$ law and is due to an increase of the rate of scattering of free electrons on the surface of a nanoparticle at a decrease of the nanoparticle size [18]. Figure $4, b$ demonstrates the broadening of the SPR band with increasing temperature. The temperature broadening is a result of the increase of the rate of electron-phonon scattering, which increases with the temperature [40, 42], as is well known.

\section{Size and Temperature Induced Shift of the SPR: Theory}

In this section, we analyze several possible mechanisms of the red shift of the SPR, when the size of nanoparticles decreases and/or the temperature of particles increases. The size and temperature effects can appear from the surface damping [19,23,48], spill-out [46], and electronic environment effects [46]. In addition, the temperature effect arises from the thermal expansion of nanoparticles [47].

Let us note that the index of refraction of silica depends on the temperature, i.e. $n$ increases with $T$ (see [49]). However, this dependence is not significant: the increase in $T$ from $300 \mathrm{~K}$ to $744 \mathrm{~K}$ results in the growth of $n$ from 1.470 to 1.475 . Such increase in $n$ would lead to a red shift of the SPR band by $0.005 \mathrm{eV}$. Meanwhile, we observed a significantly larger shift: from 0.02 to 0.07 $\mathrm{eV}$. Therefore, the observed red shift of the SPR band cannot be explained by the increase in the temperature of the silica matrix.

\subsection{Thermal expansion and surface damping}

The first possible mechanisms which can lead to the red shift of the SPR are the thermal expansion and the surface damping. Here, we develop a theoretical framework for the observed red shift of the SPR based on a simple analysis of the thermal expansion of nanoparticles and a dependence of the expansion coefficient on the temperature for silver nanoparticles.

Let the particles be much smaller than the wavelength of light $(d \ll \lambda)$. In other words, let us use the electro- 

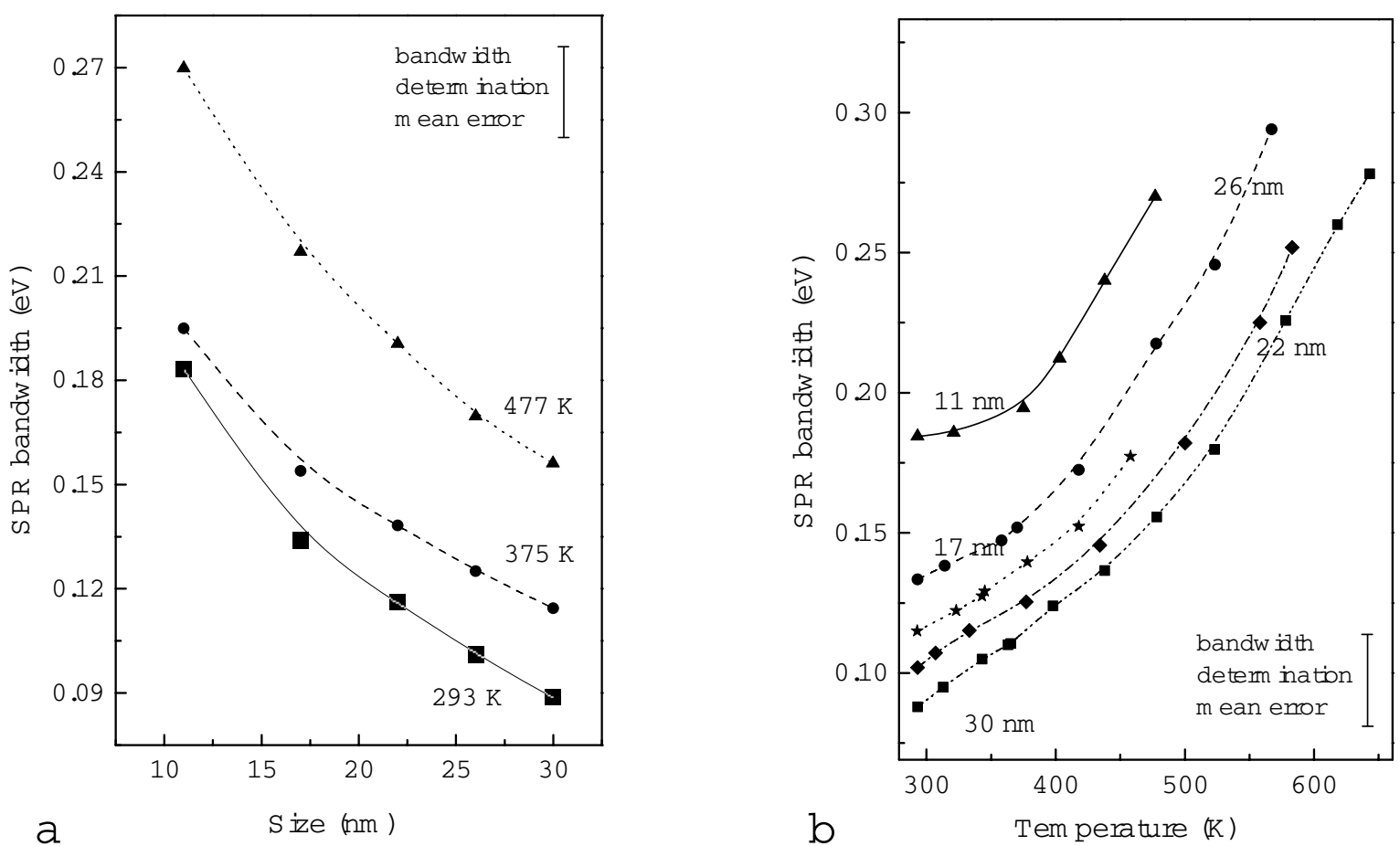

Fig. 4. (a) Size dependence of the SPR bandwidth in silver nanoparticles in silica measured at various temperatures. (b) Temperature dependence of the SPR bandwidth for silver nanoparticles of various sizes

static approximation. Then the absorption and scattering cross sections of light are given by $[18,45]$

$\sigma_{\mathrm{abs}}=4 \pi \frac{\omega}{c} \varepsilon_{h}^{1 / 2} R^{3} \operatorname{Im}\left(\frac{\varepsilon-\varepsilon_{h}}{\varepsilon+2 \varepsilon_{h}}\right)$,

$\sigma_{\mathrm{sca}}=\frac{8 \pi}{3}\left(\frac{\omega}{c}\right)^{4} \varepsilon_{h}^{2} R^{6}\left|\frac{\varepsilon-\varepsilon_{h}}{\varepsilon+2 \varepsilon_{h}}\right|^{2}$,

where $\varepsilon(\omega)=\varepsilon_{1}(\omega)+i \varepsilon_{2}(\omega)$ is the complex dielectric permittivity of the metal, $\varepsilon_{h}$ is the real dielectric permittivity of the host matrix, $c$ is the speed of light, $R$ is the radius of a nanoparticle, and $\omega$ is the frequency of an electromagnetic wave. Both the absorption and scattering cross sections have a maximum, which corresponds to the SPR energy, when the denominator reaches a minimum. The SP resonance condition (for small damping $\left.\varepsilon_{2} \ll\left|\varepsilon_{1}+2 \varepsilon_{h}\right|\right)$ reads

$\varepsilon_{1}(\omega)+2 \varepsilon_{h}=0$.

The SPR energy is then obtained by substituting the complex dielectric permittivity for a metal nanoparticle in the Drude formula

$\varepsilon(\omega)=1-\frac{\omega_{p}^{2}}{\omega^{2}-i \gamma \omega}+\varepsilon_{i b}(\omega)$ where $\varepsilon_{i b}(\omega)=\varepsilon_{i b 1}(\omega)+i \varepsilon_{i b 2}(\omega)$ is the complex contribution to $\varepsilon(\omega)$ caused by interband electronic transitions, and $\gamma$ is the scattering rate of free electrons in the metal $[18,45]$. Substituting (3) in (2) gives the expression for the SPR frequency

$\Omega_{\mathrm{SPR}}=\sqrt{\frac{\omega_{p}^{2}}{1+2 \varepsilon_{h}+\varepsilon_{i b 1}}-\gamma^{2}}$.

The plasma frequency is given by [18]

$\omega_{p}=\sqrt{\frac{n e^{2}}{\varepsilon_{0} m^{*}}}$,

where $n$ is the free electron density, $\varepsilon_{0}$ is the permittivity of the free space, $m^{*}$ is the effective electron mass, and $e$ is the electron charge. The density of free electrons in a metal particle is given by $n=N / V$, where $N$ is the number of electrons, and $V$ is the volume of a particle. The volume of a nanoparticle increases with the temperature

$V=V_{0}(1+\beta \Delta T)$,

where $\beta$ is the volume thermal expansion coefficient $\left(\beta=5.67 \times 10^{-5} \mathrm{~K}^{-1}\right.$ for bulk silver) [50], $\Delta T=$ 
$T=T-T_{293}$ is a change in the temperature, and $V_{0}$ is the particle volume at room temperature $T_{293}=293$ K. By $n_{0}$, we denote the free electron density at room temperature. Since the total number of free electrons in a nanoparticle is temperature-independent [51], i.e., $N=n_{0} V_{0}=n(T) V(T)$, we combine Eqs. (5) and (6) and obtain the following expression for the plasma frequency:

$\omega_{p}=\sqrt{\frac{n_{0} e^{2}}{\varepsilon_{0} m^{*}(1+\beta \Delta T)}}$.

Substituting Eq. (7) into (4), we obtain the SPR frequency for a metal nanoparticle:

$\Omega_{\mathrm{SPR}}=\sqrt{\frac{\omega_{p 0}^{2}}{\left(1+2 \varepsilon_{h}+\varepsilon_{i b 1}\right)(1+\beta \Delta T)}-\gamma^{2}}$.

Here, $\omega_{p 0}=\sqrt{n_{0} e^{2} / \varepsilon_{0} m^{*}}$. The damping constant for the motion of free electrons in a metal nanoparticle is $[18,19]$

$\gamma=\gamma_{\infty}+A \frac{v_{\mathrm{F}}}{R}$

where $\gamma_{\infty}$ is the scattering rate of free electrons in a bulk metal, $A$ is a constant [23], $v_{\mathrm{F}}$ is the Fermi velocity of electrons, and $R$ is the particle radius. In view of the relation between the radius and the volume of a particle $v=4 \pi R^{3} / 3$, the temperature-dependent radius of a particle is given by

$R=R_{0}(1+\beta \Delta T)^{1 / 3}$,

where $R_{0}$ is the initial radius of the particle at room temperature. The volume expansion coefficient can be a nonlinear function of the temperature $T$ [47]:

$\beta=\frac{192 \rho k_{\mathrm{B}}}{r_{0} \phi\left(16 \rho-7 k_{\mathrm{B}} T\right)^{2}}$

Here, $k_{\mathrm{B}}$ is the Boltzmann constant, and $\rho, \phi$, and $r_{0}$ are the parameters of the Morse potential used in [47] to describe the interatomic interaction potential in silver, $U(r)=\rho\left[e^{-2 \phi\left(r-r_{0}\right)}-2 e^{-\phi\left(r-r_{0}\right)}\right]$. The linear and volume expansion coefficients satisfy the relation $\alpha=\beta / 3$. Equations (8)-(11) give the expressions for the size- and temperature-dependent SPR energy, which will be used to fit the experimental results described above.

The SPR frequency is proportional to the plasma frequency, which is proportional, in turn, to the square root of the concentration of free electrons in a nanoparticle.
The concentration of free electrons decreases under the thermal expansion of a nanoparticle. Thus, the thermal expansion of a nanoparticle leads to the red shift of SPR with increasing temperature. The size dependence of the SPR frequency is described by Eqs. (4) (or (8)) and (9). A decrease of the nanoparticle size leads to an increase of the SP damping constant $\gamma \propto 1 / R$ and to a decrease of the SPR frequency, i.e., to a red shift of the SPR.

\subsection{Spill-out effect and the SPR red shift induced by the electronic environment}

In addition to the thermal expansion and the surface damping, the electronic environment effect caused by the interaction of conduction electrons with the electrons in deeper bands and the spill-out effect can cause a red shift of the SPR at a decrease of the nanoparticle size or/and at an increase of the temperature. The spill-out effect caused by a non-zero probability to find electrons outside the particles leads to a decrease of the concentration of free electrons in a nanoparticle. As one can see from Eqs. (7) and (8), this leads to a red shift of the SPR. The spill-out effect can be taken into account, by using the expression for the SPR frequency [46]

$\tilde{\Omega}_{\mathrm{SPR}}=\Omega_{\mathrm{SPR}} \sqrt{1-\frac{N_{\text {out }}}{N}}$,

where $N_{\text {out }}$ is the number of free electrons outside the geometric boundaries of a particle, and $N$ is the number of free electrons in the particle. The number of free electrons outside the particle can be calculated using the formula [46]

$\frac{N_{\text {out }}}{N}=\frac{3}{8 k_{\mathrm{F}} R} \zeta\left(\frac{E_{\mathrm{F}}}{V_{0}}, \frac{T}{T_{\mathrm{F}}}\right)$,

where $V_{0}=E_{\mathrm{F}}+W, W$ is the work function for electrons in silver, $E_{\mathrm{F}}$ is the Fermi energy, $\hbar k_{\mathrm{F}}$ is the Fermi momentum, and $\zeta\left(x, \frac{T}{T_{\mathrm{F}}}\right)$ is a monotonous function [46]

$\zeta\left(x, \frac{T}{T_{\mathrm{F}}}\right)=\zeta_{0}(x)+\zeta_{2}(x)\left(\frac{T}{T_{\mathrm{F}}}\right)^{2}$,

where $\zeta_{0}(x)$ and $\zeta_{2}(x)$ are the functions introduced in [46]. Finally, a red shift of the SPR induced by the electronic environment [46] can be written as

$\hat{\Omega}_{\mathrm{SPR}}=\tilde{\Omega}_{\mathrm{SPR}}-\delta$,

where

$\delta=\frac{3 v_{\mathrm{F}}}{4 R} j\left(\frac{E_{\mathrm{F}}}{\hbar \Omega_{\mathrm{SPR}}}, \frac{T}{T_{\mathrm{sF}}}\right)$, 

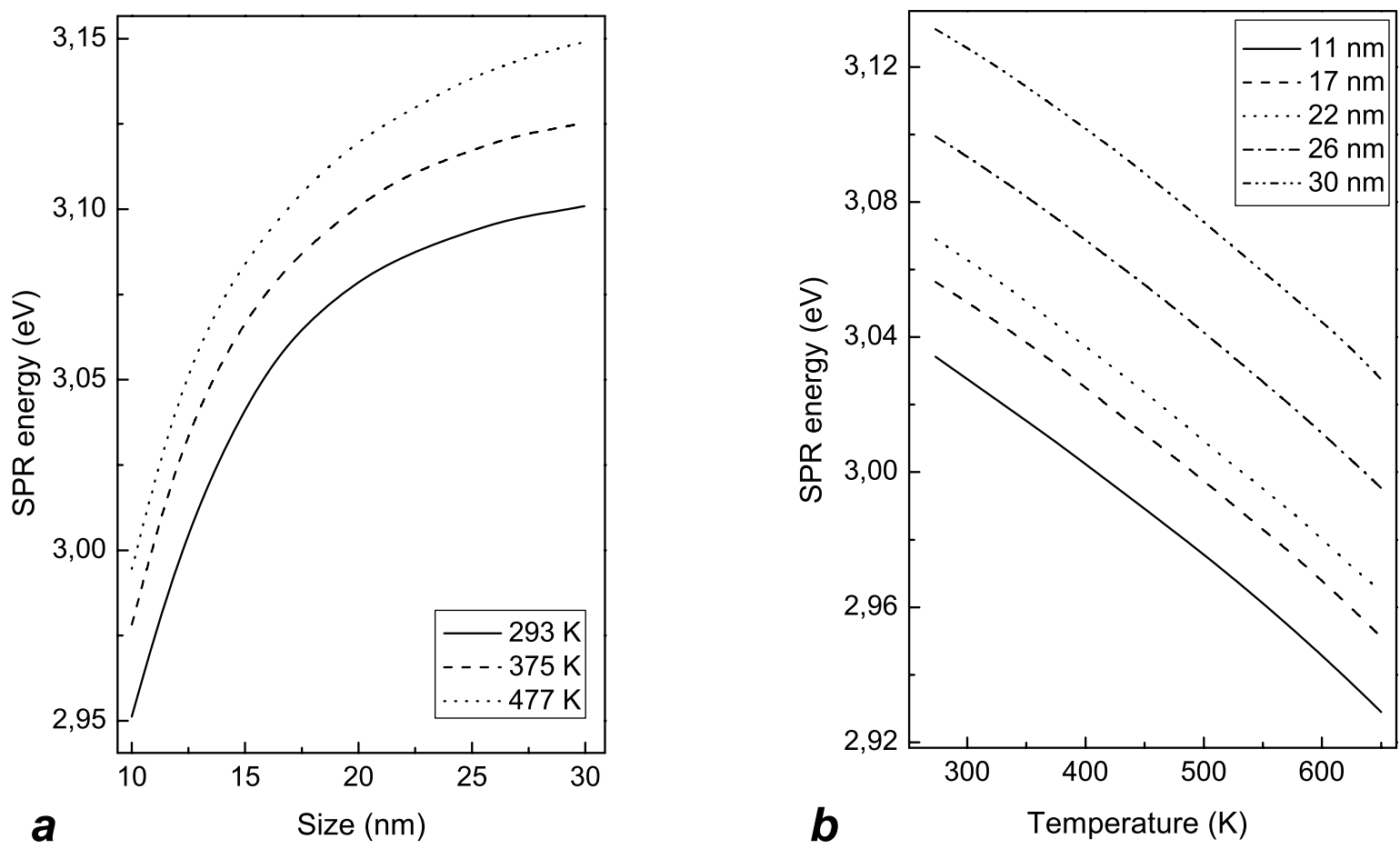

Fig. 5. (a) Calculated SPR energy for silver nanoparticles embedded in silica glass as a function of the size of nanoparticles for three different temperatures reached in the experiments. The parameters used in calculations are: $\phi=13.535 \mathrm{~nm}^{-1}, r_{0}=0.31300 \mathrm{~nm}$, $\rho=0.3257 \mathrm{eV}$ [61], $A=0.3$ (taken from fitting the experimental size dependence of the SPR bandwidth by Eq. (9)), and $\gamma_{\infty}=0.01$ $\mathrm{eV}$. (b) Calculated SPR energy as a function of the temperature for various sizes of particles used in experiments. The parameters used in calculations are the same as in Fig. 5,a

$j\left(x, \frac{T}{T_{\mathrm{F}}}\right)=j_{0}(x)+j_{2}(x)\left(\frac{T}{T_{\mathrm{F}}}\right)^{2}$ is a monotonous function, and $j_{0}(x)$ and $j_{2}(x)$ are the functions introduced in [46].

\section{Results and Discussions}

In this section, we use the theory outlined above to explain the experimental dependences of the SPR energy on the temperature and the size of silver nanoparticles.

\subsection{Size dependence of the SPR energy}

Figure 3,a shows the experimentally observed shift of the SPR band as a function of the size of nanoparticles for several temperatures of the sample $(293,375$, and 477 $\mathrm{K})$. As the size of the nanoparticles decreases, the SPR energy nonlinearly decreases (a red shift of the SPR for smaller nanoparticles). The red shift seen with decreasing the size in our experiment can be rationalized by the size dependence of the scattering rate of conduction electrons on the surfaces of nanoparticles, Eqs. (8), and (9). As the size of nanoparticles decreases, the scatter- ing rate of conduction electrons increases, Eq. (9), and the SPR energy decreases, Eq. (8). Figure 5, it a shows the results of theoretical calculations of the dependence of the SPR energy on the size of nanoparticles. We used Eqs. (8)-(11) to calculate these dependences for several different temperatures used in the experiment. The theory matches almost perfectly the experimental results as indicated in Figs. 3, $a$ and 4, $a$.

Note that a simple formula for the SPR energy as a function of the size follows from Eqs. (8) and (9). For small damping rates $\gamma \ll \omega_{\text {sp }}$ and for the small surface damping of the oscillations of free electrons as compared to the bulk one $A v_{\mathrm{F}} / R \ll \gamma_{\infty}$, which is true for silver nanoparticles within the given size range, we obtain the following approximate size dependence for the SPR energy:

$\Omega_{\mathrm{SPR}}(R)=\Omega_{\mathrm{SPR} 1}\left(1-\frac{\Lambda}{R}\right)$.

Here, $\quad \Omega_{\mathrm{SPR} 1}=\sqrt{\Omega_{\mathrm{SPR} 0}^{2}-\gamma_{\infty}^{2}}, \quad \Omega_{\mathrm{SPR} 0}=$ $\omega_{p} / \sqrt{1+2 \varepsilon_{h}+\varepsilon_{i b 1}}$, and $\Lambda=A V_{\mathrm{F}} \gamma_{\infty} / \Omega_{\mathrm{SPR} 1}^{2}$.

There are two additional mechanisms of a red shift of the SPR energy, as we mentioned in Subsection 4.2: 
the spill-out and electronic environment effects [46]. We calculated the SPR shift caused by these two effects using Eqs. (12)-(16). Our calculations indicate that the contribution of these two mechanisms to the red shift is $10^{-5} \mathrm{eV}$. This value is negligibly small as compared to the shift $\left(10^{-1} \mathrm{eV}\right)$ caused by an increase of the scattering rate of free electrons, as the size decreases, Eqs. (8) and (9). Therefore, we conclude that the red shift of the SPR, when the size of nanoparticles decreases down to about $10 \mathrm{~nm}$, which is caused only by an increase of the surface scattering rate of electrons. The spill-out and electronic environment effects do not affect the SPR energy in silver nanoparticles in the studied size range $d \geq$ $10 \mathrm{~nm}$.

\subsection{Temperature dependence of $S P R$ energy}

The increase of the temperature of nanoparticles leads to a decrease of the SPR energy, that is, to the red shift of the SPR band. Figure 3, $b$ shows the dependence of the SPR energy on the temperature for nanoparticles of different sizes $(11 \mathrm{~nm}, 17 \mathrm{~nm}, 22 \mathrm{~nm}, 26 \mathrm{~nm}$, and $30 \mathrm{~nm})$. As the temperature of the sample increases, the SPR energy decreases almost linearly for large particles $(26 \mathrm{~nm}$ and $30 \mathrm{~nm}$ ), see Fig. 3,b. As the size of the nanoparticles decreases, the red shift of the SPR energy becomes nonlinear (namely superlinear), see Fig. 3,b. We calculated the SPR energy as a function of the temperature (for the temperature interval 300-700 K), using the simple theory of temperature-dependent SPR energy outlined in Subsection 4.1 (Eqs. (8)-(11)). As the temperature of a sample increases, the volume of nanoparticles increases due to the thermal expansion, Eq. (6). The increase of the temperature leads to a decrease of the concentration of free electrons in nanoparticles and to the red shift of the SPR, Eqs. (6)-(8). The volume thermal expansion coefficient depends on the temperature, Eq. (11). The dependence of the thermal expansion coefficient on the temperature results in the nonlinear shift of the SPR, as the temperature varies. Figure $5, b$ shows the results of theoretical calculations of the temperature dependence of the SPR energy. The calculations confirm qualitatively the experimental red shift of SPR with increase of the temperature, Fig. 3, $b$. The magnitude of the SPR shift is in agreement with the experimental results. However, the theory provides the same values of shift of the SPR for all sizes of nanoparticles, Fig. 5,b. The experiment, on the other side, exhibits the linear shift only for large particles (26 nm, and $30 \mathrm{~nm})$. For smaller nanoparticles $(11 \mathrm{~nm}$, and $17 \mathrm{~nm})$, the shift becomes nonlinear. Specifically, the smaller the nanoparticles, the stronger is the nonlinearity of the SPR energy dependence on the temperature, Fig. 3,b. Our calculations do not reproduce this trend in the shift of the SPR energy.

Our simple theory outlined in Subsection 4.1 did not assume that the volume thermal expansion coefficient $\beta$ depends on the size of nanoparticles. However, some experiments suggest that the thermal expansion coefficient does depend on the size of nanoparticles [52-57]. The reported size dependence of the thermal expansion coefficient is somewhat ambiguous. Some experiments suggest that the volume expansion coefficient $\beta$ increases, as the nanoparticle size decreases [53-55]. Others report that dependence of the thermal expansion coefficient on the size $\beta(R)$ may be non-monotonic $[56,57]$. As a result, the nanoparticles of different sizes may have thermal expansion coefficients both larger and smaller than one of a bulk metal. Theoretical studies show some ambiguity too [58-60]. Some theoretical models predict an increase of $\beta(R)$ with the nanoparticle size $[58,59]$, but others indicate the opposite [60]. Thus, there are the large discrepancies and the ambiguity regarding the dependence $\beta(R)$.

Note that a simple dependence of $\Omega_{\mathrm{SPR}}$ on $T$ can be obtained when the damping is small. Taking $\beta \Delta T \ll 1$ and Eq. (8) into account, we obtain

$\Omega_{\mathrm{SPR}}=\Omega_{\mathrm{SPR} 0}\left(1-\frac{1}{2} \beta \Delta T\right)$

Therefore, given $\beta=$ const, the red shift of the SPR has to be linear when the temperature of the sample increases. However, as one can see from Eq. (11), the thermal expansion coefficient depends on the temperature. For small $\kappa \Delta T \ll 1$, the volume thermal expansion coefficient is given by

$\beta=3 \alpha \approx \beta_{0}(1+\kappa \Delta T)$,

where $\beta_{0}=3 k_{\mathrm{B}} / 4 r \phi \rho$ and $\kappa=7 k_{\mathrm{B}} / 8 \rho$. The temperature dependence of the volume thermal expansion coefficient has to lead to a nonlinear dependence of the SPR energy on the temperature:

$\Omega_{\mathrm{SPR}}=\Omega_{\mathrm{SPR} 0}\left(1-\frac{1}{2} \beta_{0} \Delta T-\frac{1}{2} \beta_{1} \Delta T^{2}\right)$,

where $\beta_{1}=\beta_{0} \kappa$. We used Eq. (20) to fit the experimental dependences of the SPR energy on the temperature for silver nanoparticles of different sizes. Taking the fitting parameters $\kappa_{0}$ and $\kappa_{1}$ obtained for different nanoparticle sizes, we calculated the volume thermal coefficients for nanoparticles of different sizes, i.e., the size 
dependence $\beta(R)$ (see Fig. 6). The calculation by Eq. (19) predicts the fivefold increase of the volume thermal expansion coefficient, as the size of the nanoparticles decreases from $30 \mathrm{~nm}$ down to $11 \mathrm{~nm}$. Note the good agreement of the calculated thermal expansion coefficient $\beta=6.34 \times 10^{-5} \mathrm{~K}^{-1}$ for the largest nanoparticles $(30 \mathrm{~nm})$ and the tabulated value $\beta=5.67 \times 10^{-5}$ $\mathrm{K}^{-1}$ for bulk silver [50]. This proves the validity of our calculation of the size dependence of the thermal expansion coefficient.

We note that the sufficiently different values of the volume thermal expansion coefficients of the silica matrix and silver nanoparticles can affect the thermal expansion of a nanoparticle as distinct from the case of the expansion of free nanoparticles. Since the respective coefficient for bulk silica, $1.8 \times 10^{-6} \mathrm{~K}^{-1}$, is sufficiently smaller that one for bulk silver, $56.7 \times 10^{-6} \mathrm{~K}^{-1}$, the silica matrix should counteract the expansion of a nanoparticle. Thus, taking into account this fact, it is most probable that the obtained values of $\beta$ for $\mathrm{Ag}$ nanoparticles are lower than the respective values for free nanoparticles. Therefore, one can suppose that, for the free Ag nanoparticles, the increase of the volume thermal expansion coefficient with a decrease of the size and an increase of the temperature should be even stronger than that for $\mathrm{Ag}$ nanoparticles embedded in silica.

As we noted above, other mechanisms that can induce a shift of the SPR band with change of the temperature are the spill-out and electronic environment effects. We calculated the spill-out and electronic environment induced shifts, by using Eqs. (12)-(16). The obtained values of the shift $\left(10^{-5} \mathrm{eV}\right)$ indicate the negligible contribution of these two effects into the temperature dependence of the SPR band shift. Therefore, we conclude that red shift of the SPR band observed, as temperature of the nanoparticles increases up to $640 \mathrm{~K}$, is caused by the thermal expansion of the nanoparticle.

\section{Conclusions}

The SPR energy in silver nanoparticles embedded in a silica glass host matrix depends on the size and the temperature of nanoparticles. Our experiments exhibit the nonlinear red shift of the SPR, as the size of he nanoparticles decreases. The increase of the surface scattering rate of free electrons causes the red shift of the SPR energy, as the particle size decreases. As the temperature of the sample increases, the SPR shifts to the red side. The volume thermal expansion of the nanoparticles leads to a red shift of the SPR. As the temperature of the particle increases, the volume of the nanoparticle increases,

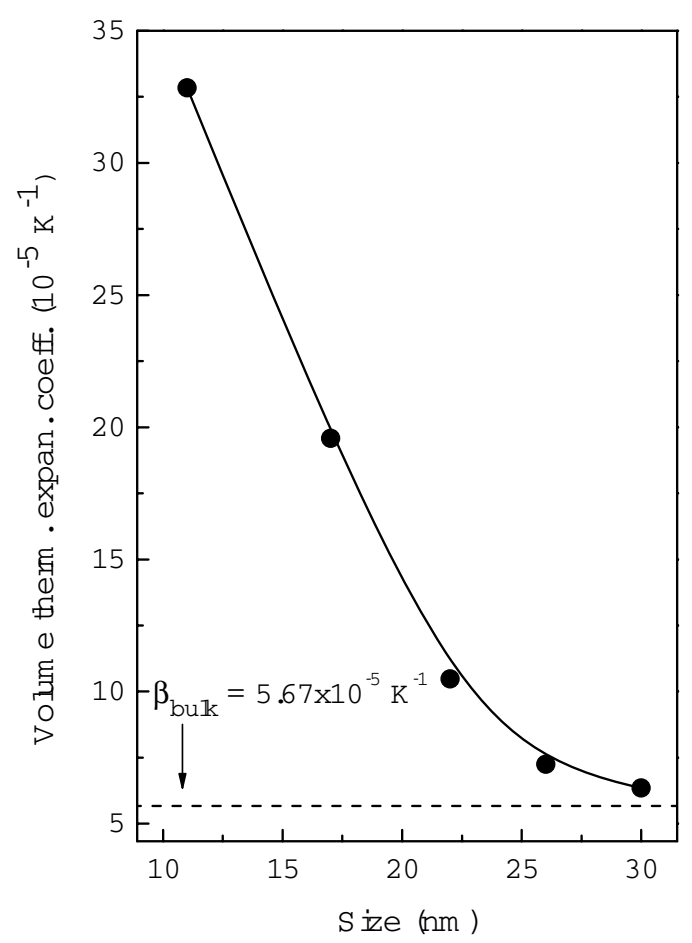

Fig. 6. The size dependence of the volume thermal expansion coefficient of silver nanoparticles in silica. Dashed line points the value of the expansion coefficient in bulk silver

and the density of free electrons decreases. The lower electron density leads to the lower plasma frequency of electrons and subsequently to the red shift of the SPR. The red shift of SPR with increase of the temperature is linear for large (25 nm and $30 \mathrm{~nm}$ ) silver nanoparticles and becomes nonlinear (superlinear) for smaller nanoparticles $(17 \mathrm{~nm}, 11 \mathrm{~nm})$. The nonlinearity of the dependence of the SPR energy on the temperature becomes stronger for smaller nanoparticles $(17 \mathrm{~nm}, 11 \mathrm{~nm})$. These two effects can be rationalized by the dependence of the coefficient of volume thermal expansion on the size and the temperature of nanoparticles, The coefficient of volume thermal expansion increases when the nanoparticle size decreases and with increase of the temperature of a nanoparticle.

The spill-out and electronic environmental effects were considered as possible mechanisms of a shift of the SPR as the temperature and the size of nanoparticles change. The calculations of the SPR shift caused by these two effects show that it is negligibly small.

The authors thank Dr. A.M. Dmytruk for the assistance in TEM measurements. This work was supported partially by the Ukrainian State Fund for Fundamental Researches and the Belarusian Republican 
Fund for Fundamental Researches under joint project F29.1/012 "Femtooptics of nanoparticles of noble metals". A.O. Pinchuk acknowledges the partial support from the UCCS through CRCW and from NSF grant DMR-0907614.

1. A. Barhoumi, D. Zhang, F. Tam, and N. Halas, J. of the Amer. Chem. Soc. 130, 5523 (2008).

2. F. Le, D. Brandl, Y. Urzhumov, H. Wang, J. Kundu, N. Halas, J. Aizpurua, and P. Nordlander, ACS Nano 2, 707 (2008).

3. G. Laurent, N. Felidj, J. Grand, J. Aubard, G. Levi, A. Hohenau, J. Krenn, and F. Aussenegg, J. of Macrosc..Oxford 229, 189 (2008).

4. R. Bakker, H. Yuan, Z. Liu, V. Drachev, A. Kildishev, V. Shalaev, R. Pedersen, S. Gresillon, and A. Boltasseva, Appl. Phys. Lett. 92, 043101 (2008).

5. G. Gay, B. de Lesegno, R. Mathevet, J. Weiner, H. Lezec, and T. Ebbesen, Appl. Phys. B 81, 871 (2005).

6. O.A. Yeshchenko, I.M. Dmitruk, A.A. Alexeenko, M.Yu. Losytskyy, A.V. Kotko, and A.O. Pinchuk, Phys. Rev. B 79, 235438 (2009).

7. A. Gobin, M. Lee, R. Drezek, N. Halas, and J. West, Clin. Cancer Res. 11, 9095S (2005).

8. C. Hubert, A. Rumyantseva, G. Lerondel, J. Grand, S. Kostcheev, L. Billot, A. Vial, R. Bachelot, and P. Royer, Nano Letters 5, 615 (2005).

9. K. Kandere-Grzybowska, C. Campbell, Y. Komarova, B. Grzybowski, and G. Borisy, Nature Meth. 2, 739 (2005).

10. M. Choi, K.J. Stanton-Maxey, J.K. Stanley, C.S. Levin, R. Bardhan, D. Akin, S. Badve, J. Sturgis, J.P. Robinson, R. Bashir, N.J. Halas, and S.E. Clare, Nano Letters 7, 3759 (2007).

11. L. Hirsch, A. Gobin, A. Lowery, F. Tam, R. Drezek, N. Halas, and J. West, Ann. of Biomed. Eng. 34, 15 (2006).

12. D. O'Neal, L. Hirsch, N. Halas, J. Payne, and J. West, Cancer Lett. 209, 171 (2004).

13. D. Citrin, Nano Letters 5, 985 (2005).

14. J. Jung, T. Sondergaard, and S. Bozhevolnyi, Phys. Rev. B 76, 035434 (2007).

15. K. Leosson, T. Nikolajsen, A. Boltasseva, and S. Bozhevolnyi, Optics Exp. 14, 314 (2006).

16. B. Steinberger, A. Hohenau, H. Ditlbacher, A. Stepanov, A. Drezet, F. Aussenegg, A. Leitner, and J. Krenn, Appl. Phys. Lett. 88, 094104 (2006).

17. J. Takahara, S. Yamagishi, H. Taki, A. Morimoto, and T. Kobayashi, Opt. Lett. 22, 475 (1997).

18. U. Kreibig and M. Vollmer, Optical Properties of Metal Clusters (Springer, Berlin, 1995).
19. A. Pinchuk and U. Kreibig, New J. of Phys. 5, 151 (2003).

20. C. Aikens and G. Schatz, J. of Phys. Chem. A 110, 13317 (2006).

21. M. Achermann, K. Shuford, G. Schatz, D. Dahanayaka, L. Bumm, and V. Klimov, Opt. Lett. 32, 2254 (2007).

22. C. Hendrich, J. Bosbach, F. Stietz, F. Hubenthal, T. Vartanyan, and F. Trager, Appl. Phys. B 76, 869 (2003).

23. A. Pinchuk, U. Kreibig, and A. Hilger, Surf. Sci. 557, 269 (2004).

24. A. Pinchuk, G. Von Plessen, and U. Kreibig, J. of Phys. D 37, 3133 (2004).

25. C. Dahmen, B. Schmidt, and G. von Plessen, Nano Letters 7, 318 (2007).

26. L.G. Grechko, A.Y. Blank, O.A. Panchenko, and A.A. Pinchuk, Telecomm. and Radio Eng. 51, 160 (1997).

27. C. Novo, D. Gomez, J. Perez-Juste, Z.Y. Zhang, H. Petrova, M. Reismann, P. Mulvaney, and G.V. Hartland, Phys. Chem. Chem. Phys. 8, 3540 (2006).

28. U. Kreibig and L. Genzel, Surf. Sci. 156, 678 (1985).

29. U. Kreibig and P. Zacharias, Zeit. für Phys. 231, 128 (1970).

30. U. Kreibig, Appl. Phys. B 93, 79 (2008).

31. W.A. Challener, C. Peng, A.V. Itagi, D. Karns, W. Peng, Y. Peng, X.M. Yang, X. Zhu, N.J. Gokemeijer, Y.-T. Hsia, G. Ju, R.E. Rottmayer, M.A. Seigler, and E.C. Gage, Nature Photonics 3, 303 (2009).

32. L.R. Hirsch, R.J. Stafford, J.A. Bankson, S.R. Sershen, B. Rivera, R.E. Price, J.D. Hazle, N.J. Halas, and J.L. West, Proceed. of the NAS of the USA 100, 13549 (2003).

33. A. Lowery, A. Gobin, E. Day, N. Halas, and J. West, Breast Cancer Res. and Treat. 100, S289 (2006).

34. A. Lowery, A. Gobin, E. Day, N. Halas, and J. West, Int. J. of Nanomedic. 1, 149 (2006).

35. L. Cao, D.N. Barsic, A.R. Guichard, and M.L. Brongersma, Nano Letters 7, 3523 (2007).

36. W. Cai, J.S. White, and M.L. Brongersma, Nano Letters 9, 4403 (2009).

37. L. G. Grechko, A. O. Pinchuk, and A. Lesjo, Proceed. of SPIE 3890, 149 (1999).

38. R.H. Doremus, J. of Chem. Phys. 42, 414 (1965).

39. S. Link and M.A. El-Sayed, J. of Phys. Chem. B 103, 4212 (1999).

40. O.A. Yeshchenko, I.M. Dmitruk, A.M. Dmytruk, and A.A. Alexeenko, Mater. Sci. and Engin. B 137, 247 (2007).

41. V.S. Gurin, A.A. Alexeenko, K.V. Yumashev, R. Prokoshin, S.A. Zolotovskaya, and G.A. Zhavnerko, Mater. Sci. and Engin. C 23, 1063 (2003). 
42. O.A. Yeshchenko, I.M. Dmitruk, A.A. Alexeenko, and A.M. Dmytruk, Phys. Rev. B 75, 085434 (2007).

43. A. Pinchuk, A. Hilger, G. Von Plessen, and U. Kreibig, Nanotechn. 15, 1890 (2004).

44. O.A. Yeshchenko, I.M. Dmitruk, A.A. Alexeenko, and A.V. Kotko, Nanotechn. 21, 045203 (2010).

45. C.F. Bohren and D.R. Huffman, Absorption and Scattering of Light by Small Particle (Wiley, New York, 1998).

46. G. Weick, G.L. Ingold, R.A. Jalabert, and D. Weinmann, Phys. Rev. B 74, 165421 (2006).

47. Z. Li-Jun, G. Jian-Gang, and Z. Ya-Pu, Chin. Phys. Lett. 26, 066201 (2009).

48. B. Grzybowski, X. Jiang, H. Stone, and G. Whitesides, Phys. Rev. E 64, 011603 (2001).

49. J.H. Wray and J.T. Neu, J. of Opt. Soc. Amer. 59, 774 (1969).

50. C. Kittel, Introduction to Solid State Physics (Wiley, New York, 2005).

51. R.H. Bube, Electrons in Solids: An Introductory Survey (Academic Press, London, 1992).

52. M. Rashidi-Huyeh and B. Palpant, Phys. Rev. B 74, 075405 (2006).

53. Y.H. Zhao and K. Lu, Phys. Rev. B 56, 14330 (1997).

54. Y. Kuru, M. Wohlschlogel, U. Welzel, and E. J. Mittemeijer, Appl. Phys. Lett. 90, 243113 (2007).

55. M. Dubiel, S. Brunsch, and L. Troger, J. of Phys.: Cond. Matt. 12, 4775 (2000).

56. W.L. Fang and C.Y. Lo, Sens. Actuat. A 84, 310 (2000).

57. M. Wagner, Phys. Rev. B 45, 635 (1992).

58. C.C. Yang, M.X. Xiao, W. Li, and Q. Jiang, Solid State Comm. 139, 148 (2006).

59. S. Pathak and V.B. Shenoy, Phys. Rev. B 72, 113404 (2005).
60. W.H. Li, S.Y. Wu, C.C. Yang, S.K. Lai, K.C. Lee, H.L. Huang, and H.D. Yang, Phys. Rev. Lett. 89, 135504 (2002).

61. R.C. Lincoln, K.M. Koliwad, P.B. Ghate, Phys. Rev. 157, 463 (1967).

Received 23.09.11

\section{PОЗМIPHA ТА ТЕМПЕРАТУРНА ЗАЛЕЖНОСТI ПОВЕРХНЕВОГО ПЛАЗМОННОГО РЕЗОНАНСУ В НАНОЧАСТИНКАХ СРІБЛА}

О.А. Єщенко, І.М. Дмитрук, А.А. Алексеєнко, А.В. Котко, Дж. Вердал, А.О. Пінчук

$\mathrm{P}$ е $з$ ю м е

Було досліджено розмірну і температурну залежності енергї поверхневого плазмонного резонансу у сферичних наночастинках срібла, інкорпорованих у кварцову матрицю, в діапазоні розмірів 11-30 нм та інтервалі температур 293-650 К. Було виявлено, що енергія поверхневого плазмонного резонансу в досліджених наночастинках срібла залежить від розміру та температури наночастинки. При зменшенні розміру наночастинки або при збільшенні їі температури спостерігається червоний зсув поверхневого плазмонного резонансу. При зменшенні розміру наночастинки збільшується частота розсіяння вільних електронів на поверхні наночастинки, що приводить до червоного нелінійного зсуву поверхневого плазмонного резонансу. Червоний температурний зсув є лінійним для великих наночастинок, але стає нелінійним для малих наночастинок. Було показано, що теплове розширення наночастинки є причиною червоного зсуву поверхневого плазмонного резонансу при збільшенні температури. Було виявлено, що об'ємний коефіцієнт теплового розширення залежить як від розміру наночастинки, так і від температури. Він збільшується при зменшенні розміру наночастинки і збільшенні температури. 